\title{
DEVELOPMENT OF THE ECOSAR P-BAND SYNTHETIC APERTURE RADAR
}

\author{
R. F. Rincon ${ }^{1}$, T. Fatoyinbo ${ }^{1}$, K. J. Ranson ${ }^{1}$, G. Sun ${ }^{1}$, M. Deshpande ${ }^{1}$, R. D. Hale ${ }^{2}$, A. Bhat ${ }^{3}$, \\ M. Perrine ${ }^{1}$, C. F. Du Toit ${ }^{1}$, Q. Bonds ${ }^{1}$, V. Marrero ${ }^{1}$, and P. James ${ }^{1}$ \\ ${ }^{1}$ NASA/Goddard Space Flight Center, Greenbelt, MD 20771 \\ ${ }^{2}$ University of Kansas/Aerospace Engineering, Lawrence, KS 66045 \\ ${ }^{3}$ Intelligent Automation Inc., Rockville, MD, 20855
}

\begin{abstract}
This paper describes objectives and recent progress on the development of the EcoSAR, a new P-band airborne radar instrument being developed at the NASA/ Goddard Space Flight Center (GSFC) for the polarimetric and interferometric measurements of ecosystem structure and biomass. These measurements support science requirements for the study of the carbon cycle and its relationship to climate change. The instrument is scheduled to be completed and flight tested in 2013.
\end{abstract}

Index Terms- SAR, Digital Beamforming, Interferometry.

\section{INTRODUCTION}

EcoSAR is an advanced airborne polarimetric and "single pass" interferometric P-band SAR instrument in development at NASA/Goddard Space Flight Center through NASA's Instrument Incubator Program (IIP). The EcoSAR design leverages the L-band Digital beamforming SAR (DBSAR) architecture which demonstrated advanced digital beamforming SAR techniques for surface imaging and biomass applications [1],[2],[3].

EcoSAR will provide two- and three dimensional fine scale measurements of terrestrial ecosystem structure and biomass. These measurements directly support science requirements for the study of the carbon cycle and its relationship to climate change, recommended by the National Science Foundation's Decadal Survey (2007) and highlited in NASA's Plan for a Climate-Centric Architecture (2010).

The primary objective of the ECOSAR is to estimate Forest biomass and Forest canopy height. Forests store 85\% of terrestrial carbon, yet the amount of carbon contained in the earth's forests is not known to even one significant figure, ranging from 385 to $6501015 \mathrm{~g}$ carbon [4] [5] [6].

EcoSAR will operate at a center frequency of $435 \mathrm{MHz}$ (69 $\mathrm{cm}$ wavelength) which allows the radar signal to fully penetrate vegetation structure and sense of the entire canopy volume and woody density. Such measurements provide the unique capability of mapping the forest cover, disturbance from deforestation and degradation, forest recovery, wetland inundation, and aboveground biomass. EcoSAR's wavelength of is also desirable for several critically important science measurements such as permafrost and ice dynamics which also support Decadal Survey objectives.

The EcoSAR instrument is currently in the second year of development. Prototype designs for the antenna, RF electronics, and digital electronics are going through a fabrication and testing stage. The antenna faring conceptual design is completed and the aerodynamic analysis of wing mounted structures is underway. It is expected that each of the EcoSAR subsystems will be completed by the spring of 2013. Testing, calibration, and system integration will take place in the spring/summer of 2013 in preparation for flight tests and two field campaigns in the 2013/2014 time frame.

\section{SYSTEM ARCHITECTURE}

EcoSAR will employ a digital beamforming architecture, a reconfigurable digital waveform generator and receiver unit, and two wideband dual-polarization array antennas with an interferometric baseline of $25 \mathrm{~m}$ on the NASA P3 aircraft [Fig1].

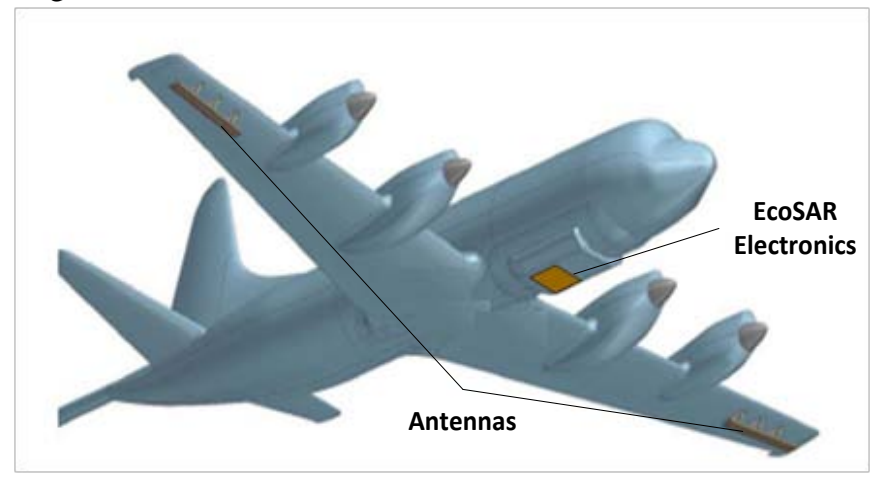

Figure 1 EcoSAR will employ advanced technology and techniques in order to enable polarimetric and interferometric measurements of biomass and ecosystem structure. 
The EcoSAR architecture will allow considerable measurement flexibility such as post processing synthesis of multiple beams, simultaneous measurement over both sides of the flight track, and variable incidence angle.

Beams can be processed with different beamwidths and side lobe levels to control swath widths and minimize side lobe contamination. Ambiguities in the receiver signal can be suppressed by post processing by appropriate nullsteering of the antenna pattern.

EcoSAR will perform cross-track interferometry in either "standard" mode or in "ping pong" mode [7] employing the two array antennas. The antennas will have dimensions of 3 $\mathrm{m} \times 0.8 \mathrm{~m}$ and will be mounted under the aircraft wings, as illustrated in Fig. 1. This configuration will provide a $25 \mathrm{~m}$ baseline in standard mode and a $50 \mathrm{~m}$ baseline in ping pong mode. These baselines are fractions of the critical baseline, therefore, minimizing any decorrelation due to the baseline.

EcoSAR will feature a fully programmable bandwidth over a $200 \mathrm{MHz}$ range. This capability will allow the instrument to adjust the range resolution according to mission requirements in a heavily used P-band environment. Operational modes with slant range resolutions from 5 meters (30 MHz bandwidth) to 25 meters (6 $\mathrm{MHz}$ bandwidth) will be used as a nominal mode in frequency restricted areas, and a science mode with slant range resolutions as fine as $0.75 \mathrm{~m}$ (up to $200 \mathrm{MHz}$ bandwidth) will be employed in authorized or remote areas. EcoSAR's main system characteristics are listed in Table 1.

\section{ANTENNA ARRAYS}

The EcoSAR antenna arrays design is very challenging since it requires wide bandwidth, high cross-polarization isolation, and scanning capability. These requirements tend to work against each other. Two different approaches are being considered for the arrays' element.

One approach uses a capacitive couple multi-probe design. Simulations of a single element have demonstrated to support $50 \%$ bandwidth and polarization isolation better than $35 \mathrm{~dB}$. However, simulation of the cross-polarization isolation in the array environment shows a significant degradation with increasing scanning angle. We are

Table 1 EcoSAR main characteristics currently working on tuning this element design to reduce cross-coupling as the array scans. Figure 2 shows the element and simulations of return loss.
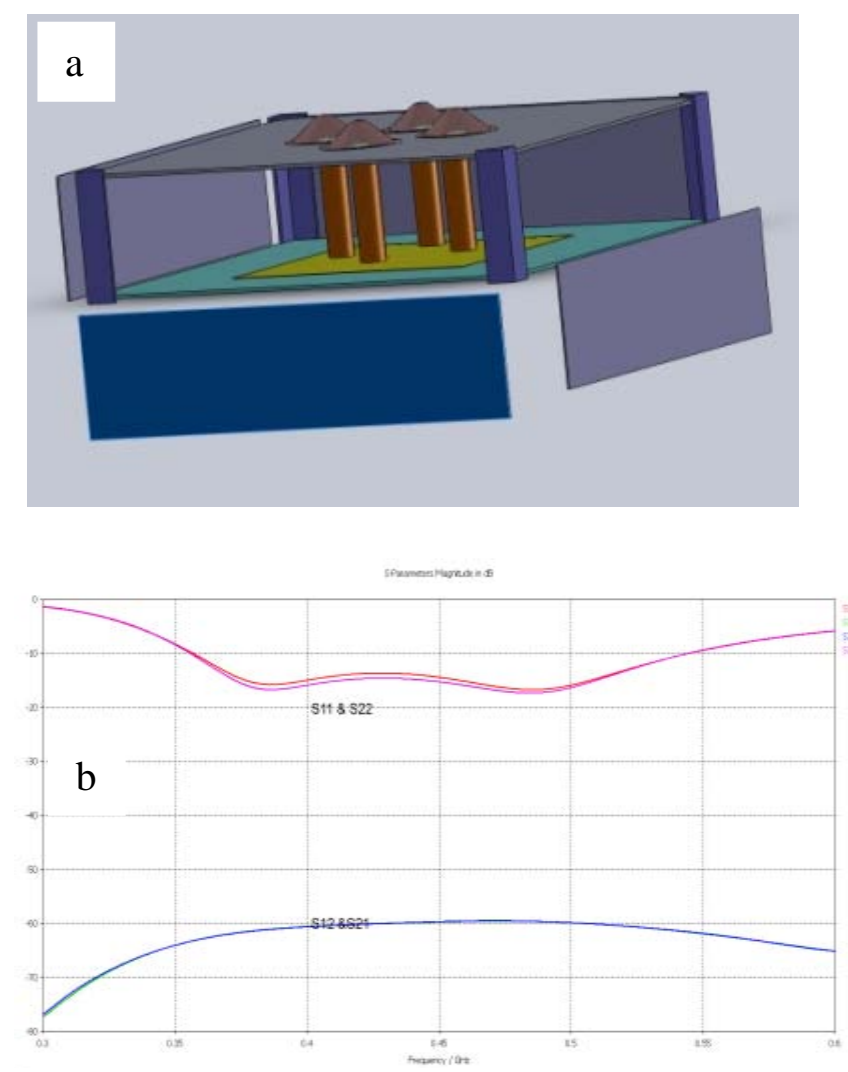

Figure 2 a) Capacitive-couple four probe antenna element and b) return loss and cross-polarization isolation.

The other approach uses a stacked patch design with microstrip line feeds. Simulations of the element in the array environment show satisfactory bandwidth, crosspolarization isolation and scanning performance. This element and simulations of return loss are shown in figure 3.

\begin{tabular}{|l|l|l|l|l|}
\hline Center Frequency & $435 \mathrm{MHz}$ & Pulse Length & 1 usec $-50 \mathrm{usec}$ \\
\hline Maximum Bandwidth & $200 \mathrm{MHz}$ & Array Peak Power & $40 \mathrm{Watts}$ \\
\hline Polarization & $\mathrm{HH}, \mathrm{HV}, \mathrm{VH}, \mathrm{VV}$ & PRF & $100 \mathrm{~Hz}-10 \mathrm{KHz}$ \\
\hline Polarization Isolation & $<-25 \mathrm{~dB}$ & Nominal Swath & $4 \mathrm{~km} *$ \\
\hline Noise Equivalent $\sigma^{\mathbf{0}}$ & $-41 \mathrm{~dB} *$ & Finest Range Resolution & $\mathbf{0 . 7 5} \mathrm{m}$ \\
\hline Total Number Channels & $\mathbf{3 6}$ & Single Look Azimuth Resolution & $\mathbf{0 . 5} \mathrm{m}$ \\
\hline Interferometric baseline & $\mathbf{2 5} \mathrm{m}$ & Vertical Accuracy & $<5 \mathrm{~m}$ \\
\hline
\end{tabular}

* from $8 \mathrm{~km}$ altitude, $35^{\circ}$ incidence angle 


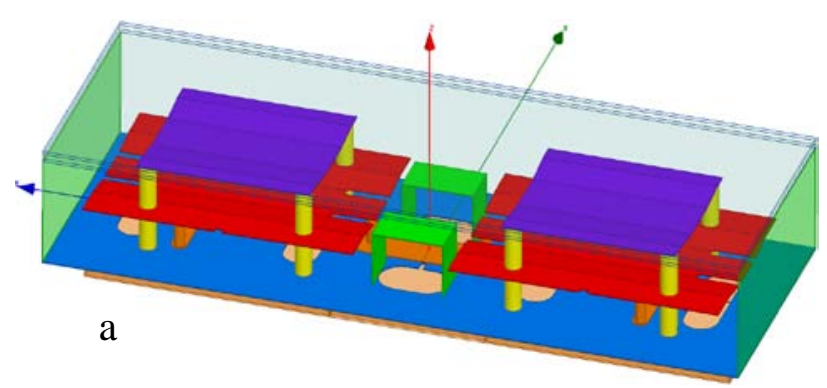

b
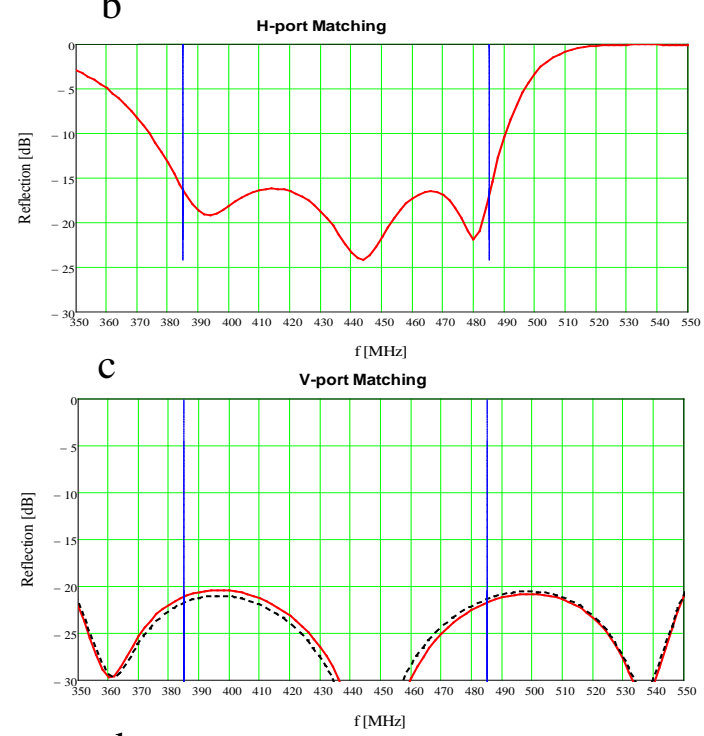

d

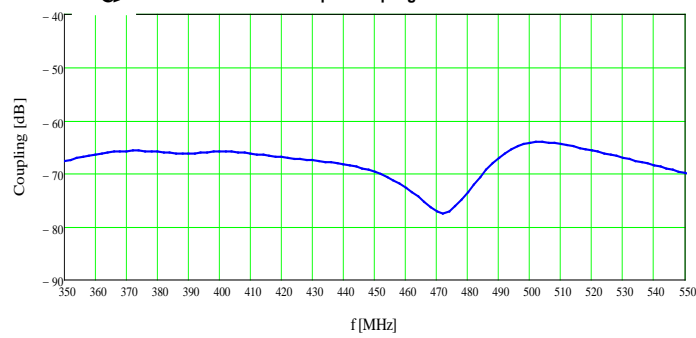

Figure 3 a) Stacked patch antenna subarray, b) and c) return loss and d) cross-polarization isolation.

The EcoSAR antenna elements will be enclosed and mount on the wings of the aircraft using a customized antenna fairing. The current fairing design consists of a metallic/composite structural fairing housing the 16 elements in a 2 x 8 configuration. Existing NASA pylons will be used to attach the fairing to the P3's outboard hard points. Preliminary analysis of the structural fairing has been satisfactory. Figure 4 shows the current structural layout of the fairing.

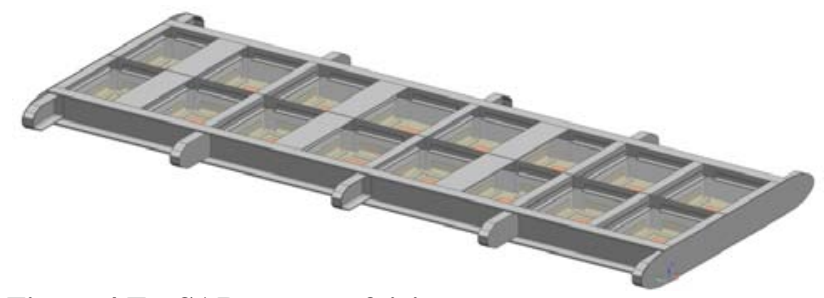

Figure 4 EcoSAR antenna fairing structure.

\section{RADAR ELECTRONICS UNIT}

The antenna arrays will be connected to the Radar Electronics Unit (REU) which will reside in the aircraft fuselage and which will include 32 transmit/receive (T/R) modules. The $\mathrm{T} / \mathrm{R}$ modules will equipped with 20 -Watt solid state power amplifiers (SSPA), low noise amplifiers (LNA), circulators, couplers, filters, and control switches, as illustrated in figure 5. They will also include closed loops for robust calibration, dynamic beam control and adaptive waveform generation.

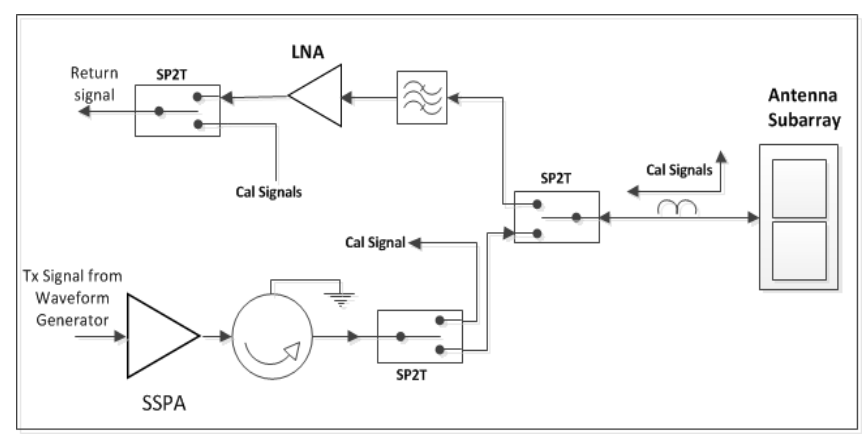

Figure 5 Simplified block diagram for EcoSAR's single channel transceiver module.

Our analysis on the types of architectures that best suit the EcoSAR system led us to select a hybrid design where the transmitter portion of the transceiver will be realized using connectorized components, while the receiver will be designed on printed circuit board (PCB) with surface mount components. This approach yields the optimum performance in terms of power, size, and efficiency.

\section{DIGITAL ELECTRONICS UNIT}

EcoSAR features an FPGA-based programmable digital waveform synthesizers system with 32 time-synchronous and phase-locked digital waveform generators (with independent amplitude and phase control), and a reconfigurable data acquisition and real-time processor with 32 independent receive channels. Figure 6 shows a simplified block diagram for the Digital Electronics Unit. 


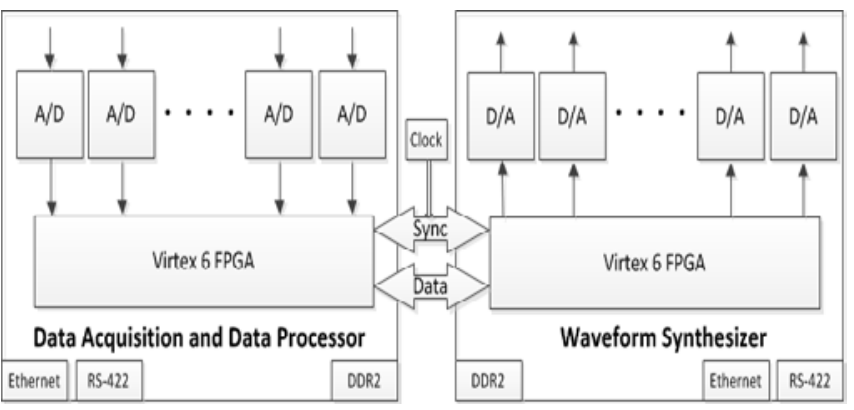

Figure 6 EcoSAR's Waveform Synthesizer, Data Acquisition and Processor Unit architecture.

The EcoSAR architecure will suport full polarimetric operation and a hybrid polarity operation (i.e., transmit circular, receive horizontal and vertical polarizations) for the retrieval of the full backscattering matrix[8]. Orthogonal polarity waveform generation techniques will also be used to implement RFI mitigation techniques.

\section{CONCLUDING REMARKS}

EcoSAR's digital beamforming, polarimetric, and "single pass" interferometric operation will make this system a first of its kind, providing unprecedented two- and threedimensional fine scale measurements of terrestrial ecosystem structure and biomass. Terrestrial ecosystems are a crucial component of the carbon cycle, and the greatest uncertainty in the global carbon cycle stems from the estimation of carbon uptake and release by terrestrial ecosystems. EcoSAR will map forest cover, above ground biomass, disturbance due to deforestation and logging, forest recovery, and wetland inundation, closing the gap in understanding the global carbon cycle.
The EcoSAR development is well underway and it is scheduled to be completed by the summer 2013 when the system will be flight tested in preparation for field campaigns.

\section{REFERENCES}

[1] Rincon, R. F.; Vega, M. A.; Buenfil, M.; Geist, A.; Hilliard, L.; Racette, P.; , "NASA's L-Band Digital Beamforming Synthetic Aperture Radar," Geoscience and Remote Sensing, IEEE Transactions on , vol.49, no.10, pp.3622-3628, Oct. 2011. doi: 10.1109/TGRS.2011.2157971

[2] Rincon, R, M. Vega, M. Buenfil, A. Geist, L. Hilliard, and P. Racette, DBSAR's First Multimode Flight Campaign, European Radar Conference, EUSAR 2010. 2010.

[3] Rincon, R., "NASAS Digital Beamforming Synthetic Aperture Radar”, 2008, IGARSS 2008 Proceedings, Boston, Massachusetts, July 6-11.

[4] Saugier, B., J.Roy, and H.A. Mooney. Estimations of global terrestrial productivity: converging toward a single number? in $\mathrm{J}$.

Roy, B. Saugier, and H.A. Mooney, editors. Terrestrial Global Productivity, Academic Press, San Diego, California, pp 543-557, 2001.

[5] Goodale, C. L., M. J. Apps, R.A. Birdsey, C.B. Field, L. S. Heath, R. A. Houghton, J. C. Jenkins, G. H. Kohlmaier, W. Kurz, S. Liu, G-J. Nabuurs, S. Nilsson, and A. Z. Shvidenko. Forest carbon sinks in the northern hemisphere. Ecological Applications, 12, pp. 891-899. 2002.

[6] Houghton, R.A., F.G. Hall, and S. J. Goetz. Importance of biomass in the global carbon cycle, Journal of Geophysical Research, VOL. 114. 2009.

[7] P. A. Rosen, S. Hensley, I. R. Joughin, F. K. Li, S. N. Madsen, E. Rodríguez, and R. M. Goldstein,"Synthetic Aperture Radar Interferometry”, Proc. IEEE, vol. 88, no. 3, pp. 333- 382, Mar. 2000.

[8] Raney, R. K., "Hybrid-Polarity SAR Architecture, 2007," IEEE Transactions on Geoscience and Remote Sensing, vol. 45, No. 11, pp. 3397- 3404. 


\title{
DEVELOPMENT OF THE ECOSAR P-BAND SYNTHETIC APERTURE RADAR
}

\author{
R. F. Rincon ${ }^{1}$, T. Fatoyinbo ${ }^{1}$, K. J. Ranson ${ }^{1}$, G. Sun ${ }^{1}$, M. Deshpande ${ }^{1}$, R. D. Hale ${ }^{2}$, A. Bhat ${ }^{3}$, M. Perrine ${ }^{1}$,
}

C. F. Du Toit ${ }^{1}$, Q. Bonds ${ }^{1}$, V. Marrero ${ }^{1}$, and P. James ${ }^{1}$

${ }^{1}$ NASA/Goddard Space Flight Center, Greenbelt, MD 20771, ${ }^{2}$ University of Kansas/Aerospace Engineering, Lawrence, KS 66045 ${ }^{3}$ Intelligent Automation Inc., Rockville, MD, 20855

\section{INTRODUCTION}

EcoSAR is an advanced airborne polarimetric and "single pass" interferometric P-band SAR instrument in development at NASA/Goddard Space Flight Center through NASA's Instrument Incubator Program (IIP).

EcoSAR will provide two- and three dimensional fine scale measurements of terrestrial ecosystem structure and biomass on board the NASA P3 aircraft.

These measurements directly support science requirements for the study of the carbon cycle and its relationship to climate change, recommended by the National Science Foundation's Decadal Survey (2007) and highlighted in NASA's Plan for a Climate-Centric Architecture (2010).

\section{INSTRUMENT RATIONAL}

EcoSAR will employ advanced technology and techniques in order to enable polarimetric and interferometric measurements of Ecosystem Structure and biomass.

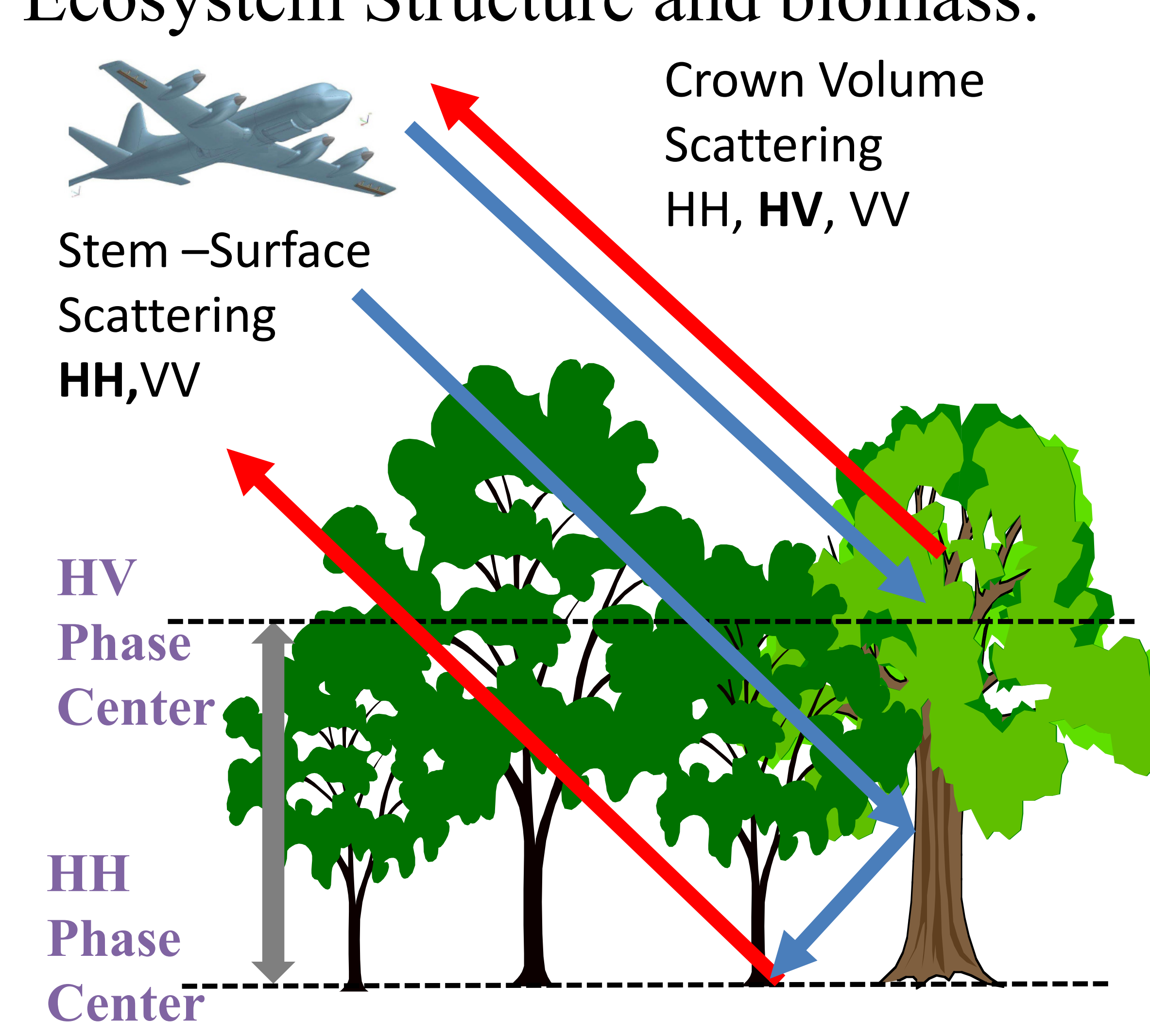

$\mathrm{P}$ - band radar signals penetrate forest structures and reflect predominately from tree trunks, large branches, and the ground.

Radar polarimetry provides information about the scattering mechanism of the forest structure, permitting the estimation of its properties and characteristics.

Synthetic Aperture Radar Interferometry (InSAR) is highly sensitive to the spatial variability of vertical structure parameters and provides quantitative information on the layered structure of the vegetation, such as the depth and density.

Polarimetric interferometric SAR (PolInSAR) combines polarimetry and interferometry providing sensitivity to the vertical distribution of scattering mechanisms. Furthermore, the variation in interferometric phase height with polarization permits to derive tree height.

\section{SYSTEM ARCHITECTURE}

EcoSAR will employ a digital

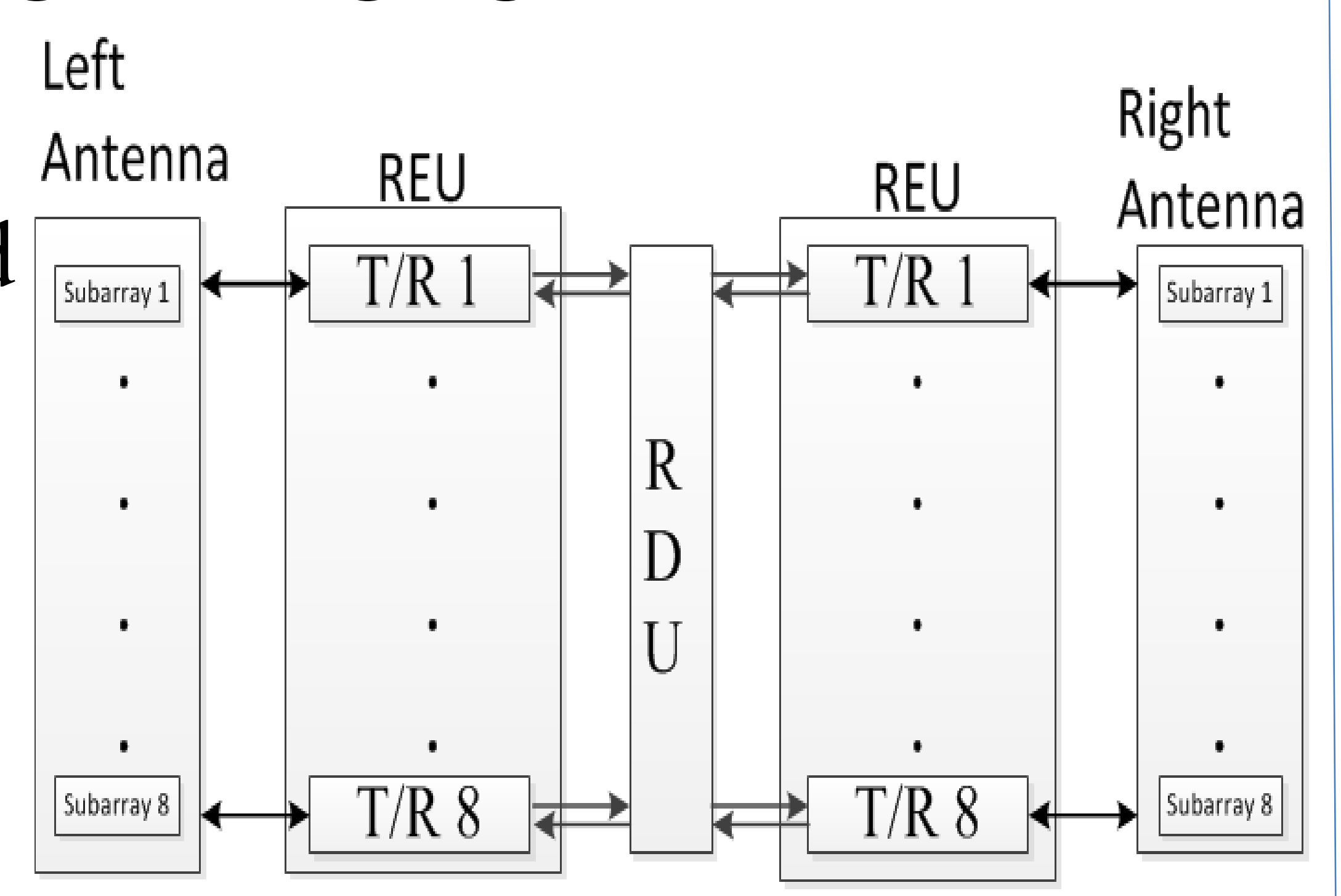

Antenna Arrays:

The two antenna arrays will be mounted under the $\mathrm{P} 3$ aircraft wings forming a baseline of 25 meters.

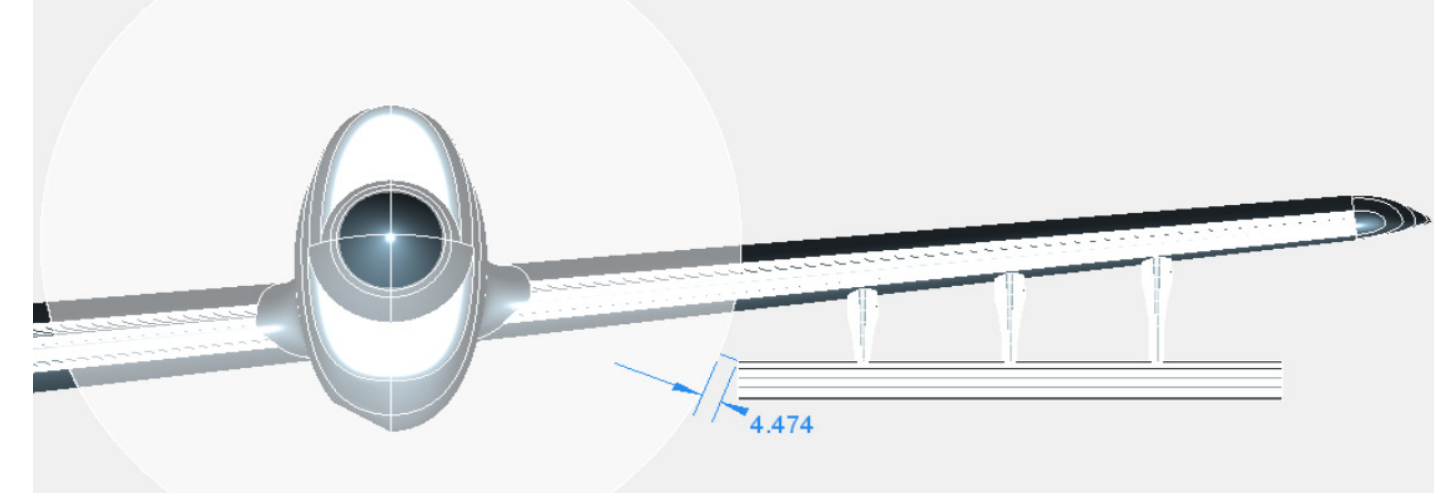

The EcoSAR antenna arrays design is very challenging since it requires wide bandwidth, high cross-polarization isolation, and scanning capability. These requirements tend to work against each other.
Two design approaches were considered for the arrays' basic element: Capacitive Coupled Patch, and Stacked Patch.

Simulations of a the capacitive coupled element model have shown to support 50\% bandwidth and polarization isolation better than $35 \mathrm{~dB}$. However, simulation of the cross-polarization isolation of the element in the array environment shows significant degradation with increasing scan angle.

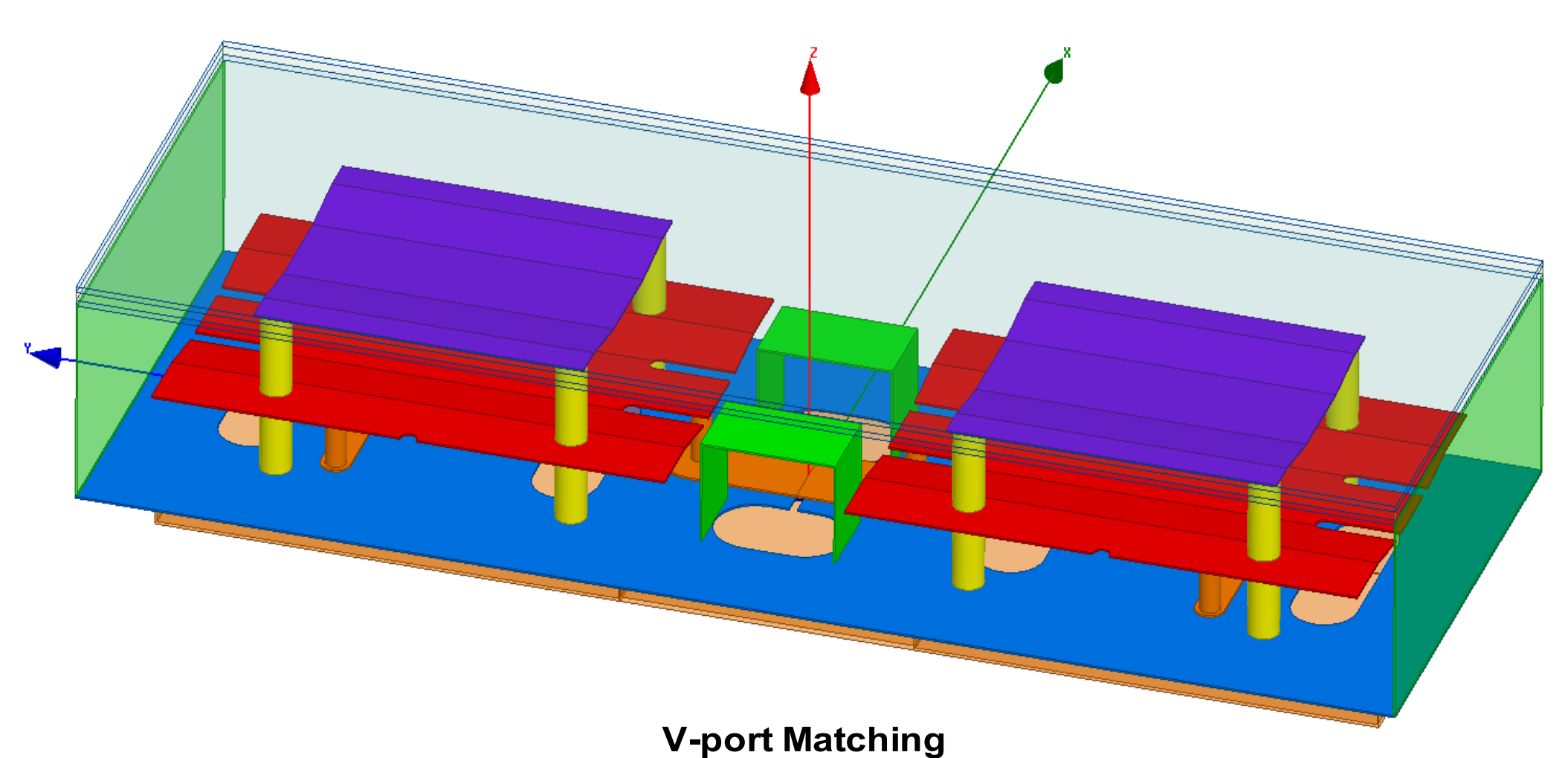

Simulations of the stacked patch design in the array environment show satisfactory bandwidth, cross-

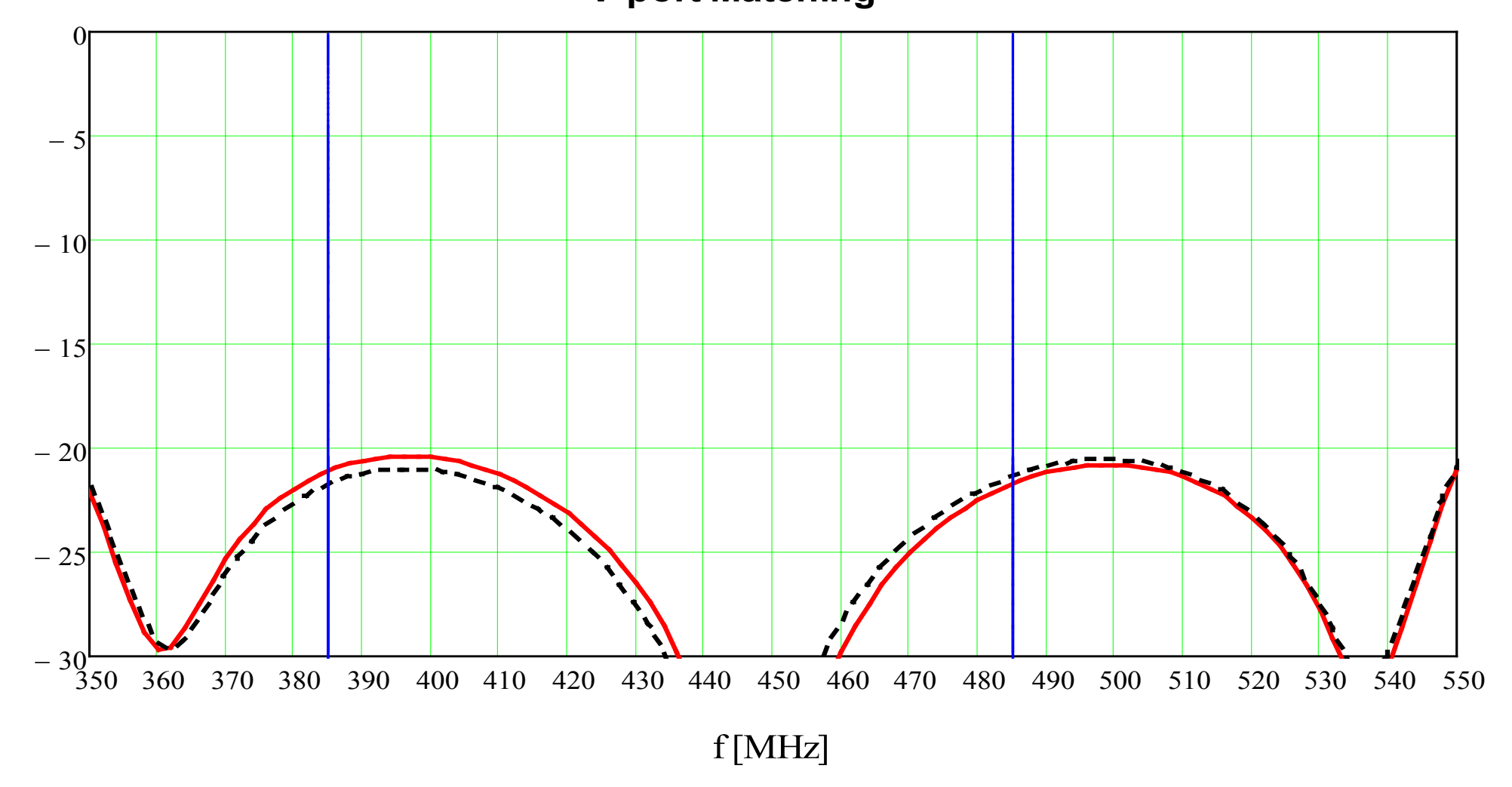
polarization isolation and scanning performance. A prototype is currently being fabricated to validate the model

\section{$\underline{\text { Radar Electronics Unit (REU) }}$}

The REU consists of 32 transmit/receive (T/R) modules which will reside inside the aircraft fuselage. The T/R modules will equipped with 20 -Watt solid state power amplifiers (SSPA), low noise amplifiers (LNA),

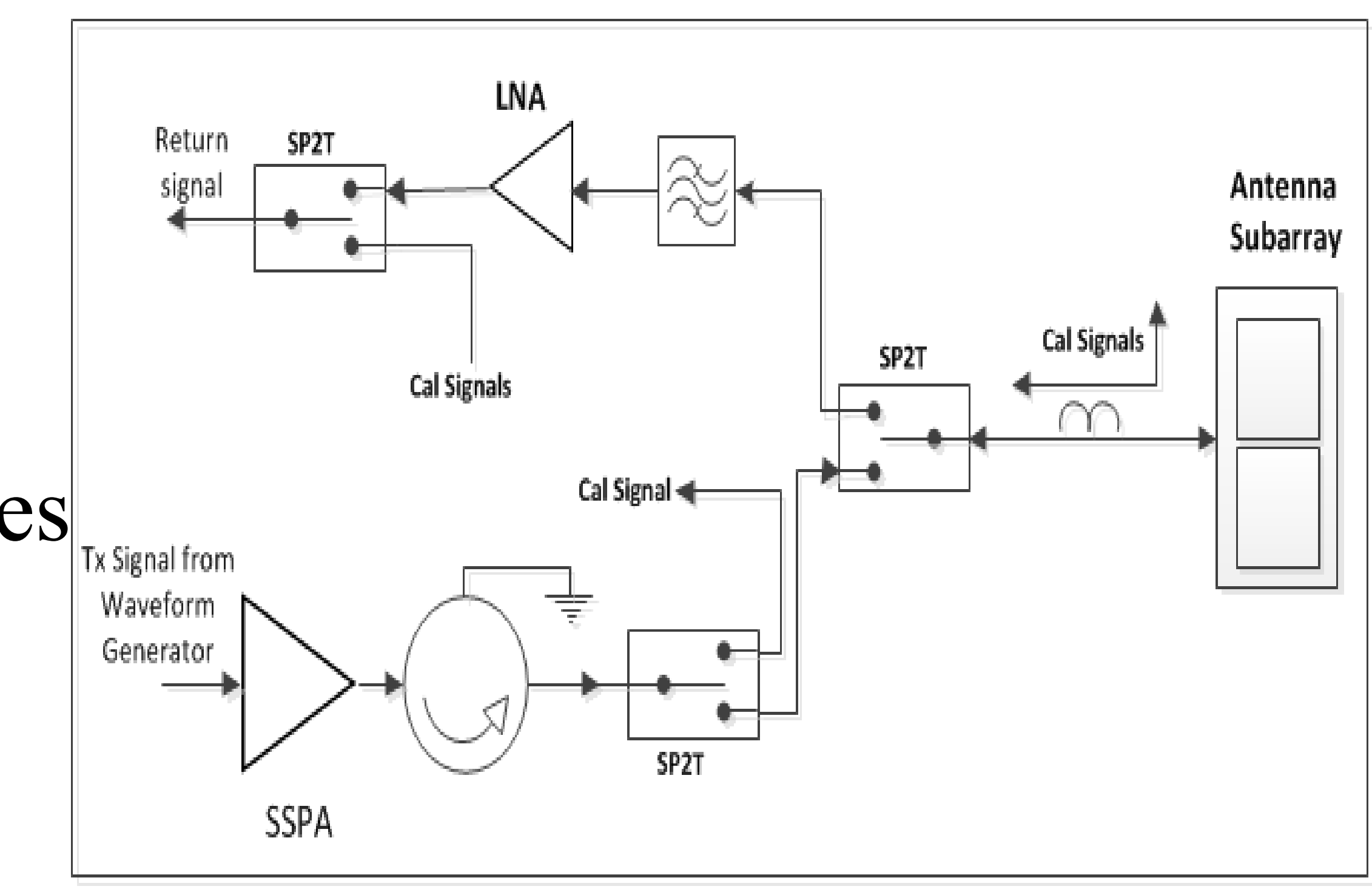
circulators, couplers, filters, and control switches.

The T/R modules will also include closed loops for robust calibration, dynamic beam control and adaptive waveform generation.

\section{$\underline{\text { Radar Digital Unit (RDU) }}$}

EcoSAR features an FPGAbased programmable digital waveform synthesizers system with 32 timesynchronous and phaselocked digital waveform Data Acquisition and Data Processor

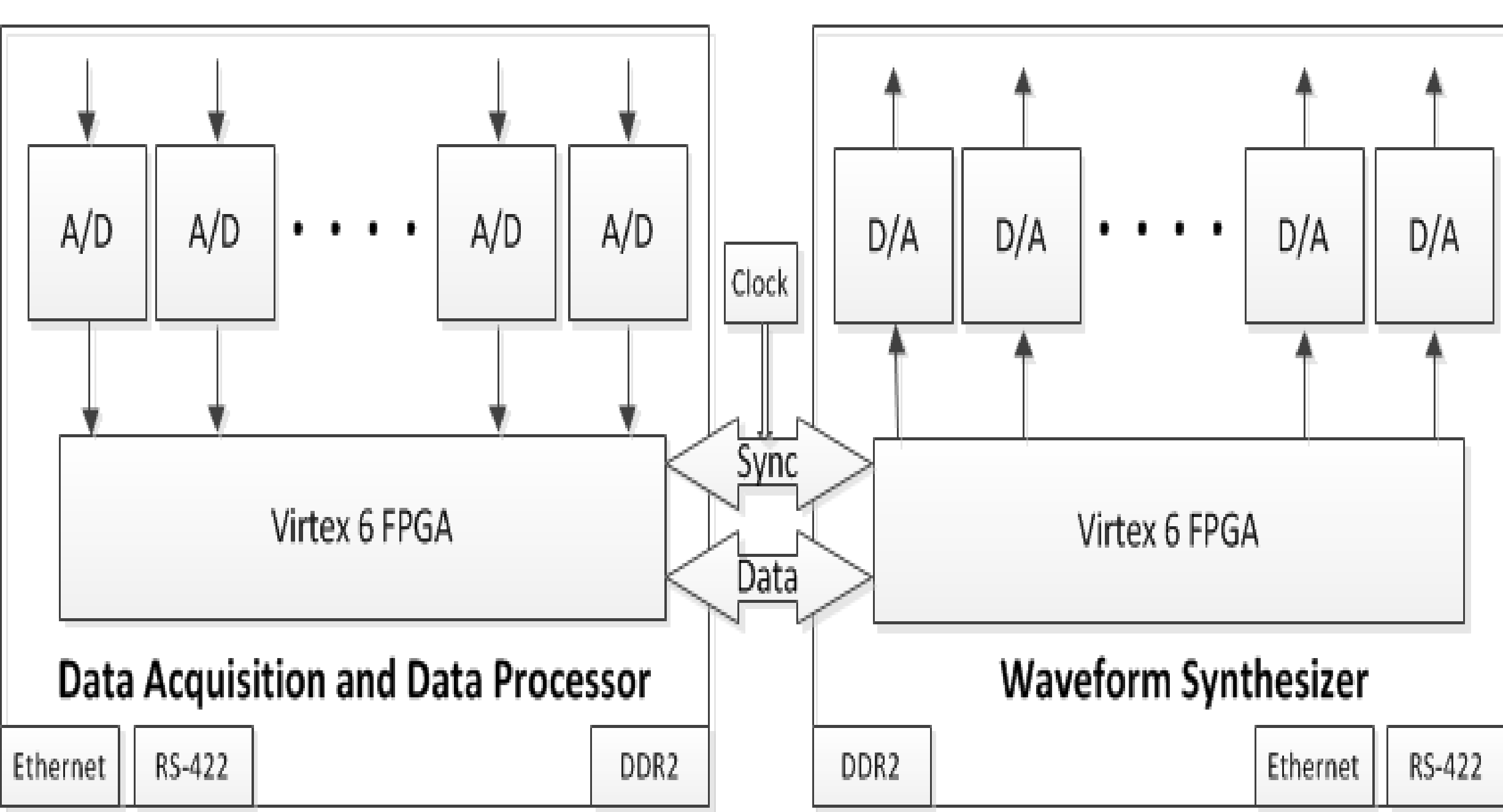
amplitude and phase control), and a reconfigurable data acquisition and real-time processor with 32 independent receive channels.

\section{CONCLUDING REMARKS}

EcoSAR's digital beamforming, polarimetric, and "single pass" interferometric operation will make this system a first of its kind, providing unprecedented two- and three-dimensional fine scale measurements of terrestrial ecosystem structure and biomass.

EcoSAR will map forest cover, above ground biomass, disturbance due to deforestation and logging, forest recovery, and wetland inundation, closing the gap in understanding the global carbon cycle. 